\title{
Emilia Pardo Bazán: Cuentos fantásticos. Edición y prólogo de Ana Abello Verano y Raquel de la Varga Llamazares. León: Eolas Ediciones, 2020.
}

La colección "Las puertas de lo posible" (Eolas Ediciones), especializada en la literatura de lo insólito, cuenta ahora entre sus producciones con una edición de los cuentos de Emilia Pardo Bazán, canónica del realismo decimonónico, presentada y editada de la mano de Raquel de la Varga Llamazares y Ana Abello Verano, investigadoras de la Universidad de León en el Grupo de Estudios Literarios y Comparados de lo Insólito y Perspectivas de Género (GEIG). En Cuentos fantásticos han venido recopilando una valiosísima producción cuentística de la autora gallega que entronca con la vertiente de lo fantástico y enlaza con el carácter analítico y de denuncia propio del naturalismo. No obstante, este volumen nos revela una Pardo Bazán pionera y aventajada respecto a sus compañeros realistas de la época, sabiendo combinar con suma habilidad y corrección todos los elementos que forman su obra, mostrándonos otra cara de lo que entendemos por realismo; un realismo en el que cada lector conforma su propia realidad a través del cauce genérico del cuento.

Así, hablar de cuento fuera del ámbito literario nos hace remontarnos a una de las formas más ancestrales de la narración humana; sin embargo, hablar del género cuentístico dentro de la tradición literaria reciente supone indagar en la devaluación que el relato breve ha sufrido en los siglos anteriores de nuestra historia. Con ello, si para más inri se quiere indagar en la producción cuentística puesta en boca de una mujer en plena época decimonónica, se observará la relegación que los cuentos de Emilia Pardo Bazán sufrieron en vida y posterior muerte de la autora hasta su revalorización en la actualidad.

Emilia Pardo Bazán (La Coruña, 1851-Madrid, 1921) comienza su andadura literaria en la órbita del realismo del siglo XIX buscando el calco fiel del mundo en su literatura; pero la misma autora acabará por superar esta tendencia inscribiéndose como naturalista, exacerbando la realidad en sus obras e indagando en los aspectos más sórdidos de su sociedad circundante. Relegada entre sus coetáneos varones, Pardo Bazán fue una pionera de su tiempo y entendía sus novelas como un estudio social, más que como un mero entretenimiento. Este cariz analítico y, en buena medida, didáctico lo imprimió también en el grueso de su producción cuentística, como se muestra a la perfección en la antología que es objeto de esta reseña, y cuya selección de cuentos permite ver desde la representación del folklore gallego hasta la denuncia de la discriminación femenina, entre otros asuntos.

Emilia Pardo Bazán sabía que la libertad creativa del género cuentístico le otorgaría la holgura y brevedad necesarias para hacer llegar el mensaje de sus relatos al lector. Baquero Goyanes, uno de los especialistas en este género, expresa convencido que el cuento pretende transmitir algo similar a lo que haría la poesía, pero en forma narrativa. Esto es así si se tienen en cuenta los rasgos fundamentales y esenciales de ambos géneros: brevedad, concisión y tensión. De esta manera, al igual que un poema, el cuento exige una lectura unitaria en la que el lector esté siguiendo el hilo conductor de los hechos y su intriga se prolongue hasta el fin del relato. Una vez acabado, el lector comprende, bien el mensaje del poema, bien la moraleja del cuento, gracias a sus diferentes recursos y técnicas. De esta forma, no es disparatado pensar que el resurgimiento del interés a nivel general por el cuento y el relato breve haya ido parejo, en muchos casos, del reflote por el gusto de la poesía en nuestros días. La literatura de 
consumo rápido, preferiblemente con un suceso único y que genere un verdadero efecto en el lector hasta el final, está en la cúspide de los gustos literarios (superando poco a poco la predominancia que había obtenido la novela en los últimos tiempos). Este resurgir por lo breve ha beneficiado a autoras como Emilia Pardo Bazán, que se han visto rescatadas de un injusto olvido histórico.

También el empleo de lo fantástico sirvió para acentuar la subestimación hacia los cuentos de la autora, pues fue visto, hasta la aparición de estudios relativamente recientes, como una categoría de segunda, relacionada con el escapismo. Sin embargo, lejos de servir para devaluar su escritura, Pardo Bazán supo emplear el territorio que le proporcionaba el mundo de lo onírico y sobrenatural para completar su retrato de los aspectos más bajos de la realidad del momento e incluso para retratar a sus personajes. No se debe pasar por alto que uno de los puntos fuertes de la narrativa de Pardo Bazán son las descripciones que hace de los personajes, llegando a incidir de una manera certera en sus personalidades y haciendo un retrato psicológico de ellos. Así, refleja cómo el elemento fantástico influye en las actitudes de los hombres y mujeres que transitan sus relatos. Se me ocurre, a modo de ejemplo, la enajenación que siente el protagonista del relato "El rizo del Nazareno" ante su incapacidad de discernir entre lo real y lo sobrenatural que lo asalta llegando casi a la locura; o, también, el trastorno mental que la autora esboza en el hombre del relato "La calavera", cuando el protagonista no puede librarse de las voces que oye en su cabeza.

Las editoras del presente volumen citan en su prólogo una frase de Tzvetan Todorov que me parece muy aguda para explicar esta cuestión; parafraseando al autor, el rasgo de lo fantástico no deja de ser la vacilación entre aceptar la explicación real o natural de los hechos o aceptar la sobrenatural que se presenta. Y en esa duda, en esa incredulidad es donde debe mantenerse el lector a lo largo del relato e interpretar a través de ella el mensaje que recibe. Sin embargo, esta cooperación de lo fantástico con el territorio realista-naturalista en el que se inscribía Emilia Pardo Bazán a la hora de retratar sus cuentos no siempre ha sido aceptada, pues había quien le achacaba una falta de realismo pleno en sus relatos por la utilización del componente fantástico (irreal en contraposición con la realidad). Pienso aquí en las palabras de Roger Garaudy cuando dice que "un realismo es insuficiente si no reconoce como real más que lo que los sentidos pueden percibir y lo que la razón puede ya explicar". ${ }^{1}$ Y constato con ellas la maestría de Pardo Bazán como realista y ferviente naturalista, ya que gracias a su componente insólito es el lector quien interviene en la historia y en el devenir de los personajes crea su propia realidad, ya que, en palabras de Maupassant, "cada uno de nosotros lleva su propia realidad". ${ }^{2}$

En añadido al empleo de lo fantástico, también se encuentra la preocupación feminista de Emilia Pardo Bazán en sus relatos. La autora se vale de nuevo del uso de lo insólito para mostrar aspectos como la sexualidad femenina, la abstinencia forzosa o el deseo, que, de no ser por el componente sobrenatural, no habrían sido permitidos de redactar. Así, el lector se encuentra ante un relato con doble sentido que deja un terreno de exploración a su imaginación. Cabe destacar que el traspase del componente religioso a uno de cariz sexual que Pardo Bazán emplea en algunos de sus cuentos ya había sido dilucidado por especialistas

\footnotetext{
${ }^{1}$ AMORÓs, Andrés (1979): Introducción a la literatura. Madrid, Castalia: 56.

${ }^{2}$ Ibid., 59.
} 
en autoras como Santa Teresa de Jesús, de la que algunos estudios dicen que en sus Éxtasis se puede hacer una trasposición del ámbito sacro al profano. Algo así ocurre con "Las espinas", que, como señalan Raquel de la Varga y Ana Abello, requiere una lectura entre líneas, pues es el lector quien debe decidir si hacer un cambio de planos para entender el verdadero contenido del relato.

Otro rasgo primordial en la producción cuentística de la autora gallega es la ambientación de sus relatos en su Galicia natal, concretamente en las dimensiones rurales, mostrando los aspectos más ásperos de la sociedad rural del momento. Pardo Bazán sabe aprovechar el misticismo de los bosques frondosos de Galicia y se vale de una rica tradición sobrenatural. Además de esto, considero que lo primordial en lo que el lector debe fijarse a la hora de interpretar el enclave gallego que retrata la autora es que pretende, grosso modo, un efecto catártico, además de una crítica, en quien la lee, pues denuncia las muchas veces duras condiciones y robusteces de las tradiciones populares para emprender una mejora en la vida de las gentes de su tierra.

En síntesis, podría decirse que Emilia Pardo Bazán combinó en sus relatos todas las preocupaciones que volcó en sus novelas, con la salvedad de que sus cuentos breves canalizaron más la denuncia que pretendía expresar por la prestación a ello de dicho género. Sus personajes están perfectamente adecuados a la trama única que circunda el relato y en ellos se vuelca el peso de la acción, ya que son los mismos individuos quienes portan la moraleja de la historia. Los ambientes gallegos ayudan a la introducción en el territorio sobrenatural presentado por la sensación que de ellos extrae el lector, y el empleo de lo fantástico permite la visualización y puesta en escena de las vicisitudes y denigraciones que aún sufrían las mujeres coetáneas a Pardo Bazán; la autora es una feminista de su tiempo y no solo en el plano literario plasmó sus reivindicaciones, sino que fue una mujer de acción que intervino también en el plano real.

Finalmente, y enlazando de manera circular con la introducción, quiero resaltar la suma importancia que tiene, en mi opinión, el giro conceptual que Emilia Pardo Bazán dio a la definición del realismo imperante, de la que se ha hablado a lo largo de estas líneas, y que ha quedado patente y dilucidada en cuentos como los que recoge el presente volumen. La importancia del lector, su intervención y la visión de que no solo existe una realidad (incluso cayendo en el posterior escepticismo de autores del nouveau roman francés que niegan el arte realista) será un tema arduamente trabajado por la tradición literaria posterior y no sería excéntrico afirmar que Emilia Pardo Bazán es una de las autoras que abren el camino en este nuevo realismo de explorar varias realidades partiendo de "lo otro" o lo desconocido.

La edición preparada por Eolas invita a adentrarse en todo este mundo que he ido desmenuzando poco a poco gracias al copioso y esmerado trabajo de Raquel de la Varga y Ana Abello de homenajear y revalorizar, como sus títulos merecen, a una autora del talante y prestigio de Emilia Pardo Bazán.

Paula Barba del Pozo

Universidad de Salamanca paulabarba@usal.es 
DOI: https://doi.org/10.24029/1ejana.2022.15.3561

Recibido: el 21 de noviembre de 2021

Aceptado: el 16 de diciembre de 2021

Publicado: el 25 de febrero de 2022

(C) Paula Barba del Pozo

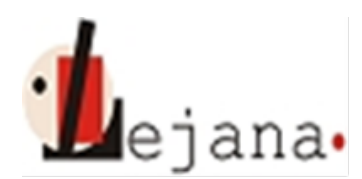

http://ojs.elte.hu/index.php/lejana

Universidad Eötvös Loránd, Departamento de Español, 1088 Budapest, Múzeum krt. 4/C 